How to cite this article: Jamali, H. R. and Nicholas, D. (2008), "Information-seeking behaviour of physicists and astronomers", Aslib Proceedings, 60, (5), 444-462.

Article DOI: 10.1108/00012530810908184

\title{
Information-seeking behaviour of physicists and astronomers
}

Hamid R. Jamali

CIBER, Department of Educational Technology, Faculty of Psychology and

Education, Tarbiat Moallem University, No 49, Mofateh Ave, P.O.Box: 15614, Tehran, Iran

h.jamali at gmail.com

David Nicholas

CIBER, School of Library, Archive and Information Studies, University College

London, Henry Morley Building, Gower Street, London WC1E 6BT

\begin{abstract}
Purpose - The study examines two aspects of information seeking behaviour of physicists and astronomers including methods applied for keeping up-to-date and methods used for finding articles. The relationship between academic status and research field of users with their information seeking behaviour was investigated.

Methodology/approach - Data were gathered using a questionnaire survey of $\mathrm{PhD}$ students and staff of the Department of Physics and Astronomy at University College London; 114 people (47.1 per cent response rate) participated in the survey.

Findings - The study reveals differences among subfields of physics and astronomy in terms of information-seeking behaviour, highlights the need for and the value of looking at narrower subject communities within disciplines for a deeper understanding of the information behaviour of scientists.

Originality/value - The study is the first study to deeply investigate intradisciplinary dissimilarities of information-seeking behaviour of scientists in a discipline. It is also an up-to-date account of information seeking behaviour of physicists and astronomers.

Keywords - Physics, Astronomy, Information-seeking behaviour, User studies, Information behaviour

Paper Type - Research paper
\end{abstract}

\section{Introduction}

How do scientists really discover, select and use the countless information and communications resources available to them? Studying the information behaviour of scientists has been one of the main concerns of librarians and information scientists at least since The Royal Society Scientific Information Conference of 1948 (Royal Society, 1948). As information technologies, which nowadays are major means of information service provision, develop, information services are improved and as a result information seeking activities of scientists go though changes and adjustments. This is a cycle where research on information behaviour of scholars leads to better information services and improved information services might make the scholars alter 
their information seeking activities and behaviour, hence the need for continuous study of the information-seeking behaviour of scholars.

[end of page 444]

Physicists are renowned for their information prowess. They have played a significant role in scholarly communication and publishing, especially in areas such as e-print culture and electronic publishing. They are renowned for having one of the, apparently, most efficient information systems (Nicholas et al., 2005a) and the best organised literature in sciences (Gould and Pearce, 1991, cited in Lawal, 2002). They are known as innovators in methods of scholarly communication (Wertman, 1999). Physics and astronomy are expensive sciences. Nowadays, conducting research in certain areas of physics and astronomy is not feasible for countries unless they are done as multinational collaborative projects. The financial factors and the collaborative nature of the research in many areas of physics and astronomy necessitate the importance of an efficient information system. The supply and the maintenance of such a system require up-todate knowledge of scholars' information-seeking behaviour which is only achievable by researching this area. Therefore, not surprisingly physicists and astronomers have been the subject of much information science interest. This paper perpetuates that interest but is somewhat unusual in one respect: it takes a closer look within physics and astronomy than has been the case hitherto.

\section{Aims and objectives}

The study aims to look at differences and similarities between different research areas within physics and astronomy with regard to two aspects of information-seeking behaviour, including methods used for keeping up-to-date and methods used for identifying articles.

\section{About UCL department}

The UCL department is a research oriented department that at the time of data collection of this study (2005-06) had about 150 academic and research staff and more than 100 research students.

The department consisted of four research areas and contributed to six research centres that each had their own researchers. The four research areas were:

Astronomy, Astrophysics and Atmospheric Physics

Atomic, Molecular, Optical and Positron Physics

Condensed Matter and Materials Physics

High Energy Physics

Although the main structure of the department was based on the four aforementioned research groups, some of these groups were composed of smaller research groups that were quite characteristic and could be studied separately rather than as part of the bigger research group. For instance, although Atmospheric Physics is part of the broader research group "Astronomy, Astrophysics and Atmospheric Physics” (the first research group), it is a quite distinctive research group with its own laboratory and research areas that are not very related to astronomy. Or in the case of the second research group "Atomic, Molecular, Optical and Positron Physics", two subgroups of "Optical Science Laboratory" and "Theoretical Molecular Physics" could be separated as two distinctive groups. Therefore the researchers have decided to consider the following seven research 
groups as the research areas in the department and units of analysis in this study wherever appropriate.

[end of page 445]

- $\quad$ Atmospheric Physics (AP)

- $\quad$ High Energy Physics (HEP)

- $\quad$ Condensed Matter and Materials Physics (CMMP)

- $\quad$ Astronomy and Astrophysics (AA)

- $\quad$ Theoretical Molecular Physics (TMP)

- $\quad$ Atomic, Molecular, Optical and Positron Physics (AMOP)

- $\quad$ Optical Science Laboratory (OSL)

\section{Literature review}

Not many studies have been done on the information-seeking behaviour of physicists and astronomers and the methods they utilise for finding information. A rather old study by Ellis et al. (1993), before the popularity of the web-based information services, investigated the information-seeking patterns of a group of social scientists, physicists and chemists using the grounded theory approach. They did not find fundamental differences among these groups, surprising perhaps. Therefore they concluded that overall differences between the information seeking activities of the chemists, physicists, and social scientists seemed more a difference of emphasis than of a fundamental difference in behaviour. They identified five main features for the information-seeking behaviour of these groups with slightly different terminologies. For the physicists these five core features were: initial familiarization, chasing, source prioritization, maintaining awareness, and locating. These five features are known as Ellis' model of information-seeking behaviour.

Regarding applied methods for finding less recent information, a survey of astronomers, chemists, mathematicians, and physicists at the University of Oklahoma by Brown (1999a) found that physicists and astronomers used citations at the end of articles (94 per cent), retrospective searching of indexing/abstracting tools (56 per cent), personal communication (50 per cent) and browsing older volumes (19 per cent). Eighty-one per cent of respondents in the field of physics/astronomy said that they photocopied the library's copy for obtaining journal articles, 75 per cent read the library's copy, 44 per cent used free electronic copy, the same percentage used interlibrary loans, 38 per cent had a personal subscription, and 19 per cent used the library's electronic subscriptions.

Nicholas et al. (2005b) surveyed the users of the Institute of Physics (IoP) journals to report on the views and attitudes of physicists around the world in relation to what they get and want from the journals system. Their aim was, in particular, to assess how they use electronic products and services. The findings showed that the most frequent method used to locate journal articles was visiting a journal's web site. Respondents said they were most dependent on visiting a journal's web site for finding articles followed by the library. Younger respondents were more likely to rely on the Web of Science, while older respondents were likely to depend on their personal collection. In general, younger users were more likely to depend on and use online methods. The most important web site proved to be the arXiv e-print server and this was followed by Elsevier ScienceDirect. 
Another study by Nicholas et al. (2006) that utilised both log analysis technique and online survey to study the information-seeking behaviour of ScienceDirect's authors (as users) revealed some information about physicists in comparison to scientists [end of page 446] in other fields. Physicists, compared to respondents from other subjects, were more likely to be browsers than searchers - they obtained much information by requesting journal homepages and journal issues. Physicists were also more active, making a higher number of requests in a session.

Brown (1999a) surveyed astronomers, chemists, mathematicians and physicists at the University of Oklahoma and found that physicists and astronomers mostly used current journals and had reliance on pre-print archives. Mathematicians and physicists/astronomers used personal communication and conference attendance but chemists used current awareness services. This study also shed some light on the different sources of reading used for different purposes. It turned out that for teaching purposes, physicists and astronomers relied 93 per cent on textbooks, 40 per cent on journals, 6 per cent on preprints, 6 per cent on conference attendance and 13 per cent on personal communications, while these figures for research purposes were respectively 33, 87, 67, 60, and 33 per cent.

A year after Brown's study, Cho (2000) investigated the sources of reading by physicists and concluded that astrophysicists have virtually replaced journal reading with regular inspection of the Astrophysics archive at arXiv.org. More recent studies by Tenopir and King (2002) found that the number of readings per scientist across all work fields increased from an average of 100 articles per year in mid-1990s to 130 per year in the early 2000s. A survey in 2000 showed that physicists read an average of 204 articles per year and spend 153 hours per year reading on average.

In general, physicists and astronomers are heavy users of e-print archives (Kling and McKim, 2000; Fry, 2003). According to Lawal (2002) this high usage of e-print archives is because theoretician physicists depend on the work of their predecessors. The information most important to them is often too recent to have been published; hence they use e-print archives.

As the literature review shows there have not been any studies on similarities and differences among different subfields of physics and astronomers in terms of their information seeking behaviour. All of the studies on physics consider the whole field as a single discipline without investigating areas within physics or astronomy. This study tries to fill this gap.

\section{Methodology}

The data presented here was obtained from a mixed-method research project conducted as a $\mathrm{PhD}$ thesis (Jamali, 2008). The research included interviews, critical-incident data, as well as a questionnaire survey of staff and PhD students in the Department of Physics and Astronomy at University College London (UCL). This article presents part of the findings of the survey study.

A self-administered web-based questionnaire was designed for conducting the survey. The questionnaires went online on 3 May, 2006. To conduct the survey, a personalised 
e-mail was sent to all staff and $\mathrm{PhD}$ students in the department with a link to the questionnaire. This was followed by two sets of reminder e-mails with about ten day intervals.

There was no need for sampling in the survey as it was possible to include all $\mathrm{PhD}$ students and staff in the Department of Physics and Astronomy at UCL in the survey. However, the respondents were self-selective due to what is known as the phenomenon of non-response. This phenomenon refers to the difference between the initial sample (all [end of page 447] individuals about whom we want to collect information) and the final sample (the cases we manage to get information on). This phenomenon is composed of different aspects including refusal to participate (because of lack of time or other personal reasons) in a survey or to be interviewed (Gobo, 2004, p. 441). As the participation in the survey was voluntary, the refusal by some to take part in the questionnaire was the main reason for the non-response phenomenon in this study. There were 129 staff and $113 \mathrm{PhD}$ students (total 242 people) in the department and the survey achieved 47.1 per cent response rate with 114 respondents, which is a good rate by any standard as Hemminger et al. (2007) showed that participation rates range from 3 per cent to 62 per cent for electronic surveys.

\section{Findings}

Characteristics of the sample

Seventy-one per cent (81) of respondents were male and 29 per cent (33) were female. This was a reflection of the general population of the department, of which 75 per cent were male academics and research students. A high percentage of respondents as we can see in Table I were research students (57 per cent) followed by research fellows (17 per cent). There were also ten professors among the respondents.

Table I. Distribution of the respondents by academic status

\begin{tabular}{lcc}
\hline Academic Status & No & \% \\
\hline PhD Student & 65 & 57 \\
Research Fellow & 20 & 17.5 \\
Senior Researcher & 6 & 5.3 \\
Lecturer & 11 & 9.6 \\
Reader & 2 & 1.8 \\
Professor & 10 & 8.8 \\
\hline Total & $\mathbf{1 1 4}$ & $\mathbf{1 0 0}$ \\
\hline
\end{tabular}


Table II. Distribution of the respondents by type of research

\begin{tabular}{lcc}
\hline Type of Research & No & \% \\
\hline Theory (physics) & 36 & 31.6 \\
Experiment (physics) & 33 & 28.9 \\
Observation (astrophysics \& astronomy) & 13 & 11.4 \\
A bit of both & 10 & 8.8 \\
Theory (astrophysics \& astronomy) & 18 & 15.8 \\
Instrumentation & 4 & 3.5 \\
\hline
\end{tabular}

Table II shows the distribution of respondents by the type of their research. The highest number of respondents belonged to those involved in theoretical research in the field of physics (31.6 per cent), followed by 33 respondents (28.9 per cent) who did experimental research in physics. The smallest proportion belonged to those who did instrumentation research with only four respondents who fell into this category. Seven main subfields of physics and astronomy (research group entities inside the department) were used to categorise the respondents (Table III). CMMP accounted for 31.6 per cent of the respondents. CMMP is the biggest research group in the department and it encompasses a considerable number of smaller research groups that [end of page 448] research on very specific topics. After CMMP, AA accounted for the second highest number of respondents with 22 (19.3 per cent) respondents. This research group also covers many smaller research groups such as hot stars, star formation and so on. The smallest number of respondents belonged to the OSL with three respondents who all do instrumentation-kind of research.

Table III. Distribution of the respondents by research group

\begin{tabular}{lcc}
\hline Research Group & No & \% \\
\hline Atmospheric Physics (AP) & 11 & 9.6 \\
High Energy Physics (HEP) & 18 & 15.8 \\
Condensed Matter and Materials Physics (CMMP) & 36 & 31.6 \\
Astronomy and Astrophysics (AA) & 22 & 19.3 \\
Theoretical Molecular Physics (TMP) & 11 & 9.6 \\
Atomic, Molecular, Optical and Positron Physics (AMOP) & 13 & 11.4 \\
Optical Science Laboratory (OSL) & 3 & 2.6 \\
\hline Total & $\mathbf{1 1 4}$ & $\mathbf{1 0 0}$ \\
\hline
\end{tabular}

\section{Keeping up-to-date}

The results presented in this section are based on the following three questions that the participants were asked: 
In your subfield, how important is rapid awareness of new papers?

(Not at all important/ A little important/ Somewhat important/ Quite important/ Absolutely critical/ I don't know)

How dependent are you on each of these methods for keeping up-to-date with developments in your subfield?

(Scales: Very dependent/ Quite dependent/ Not very dependent/ Not at all dependent)

Browsing electronic journals

Browsing print journals

Browsing preprint archive

Receiving journals' table of contents e-mail alerts

Receiving e-mail alerts from preprint archives

Receiving search e-mail alerts (like the service of Web of Knowledge)

Newsletters

Departmental or groups' seminars and meetings

Conferences

Word of mouth and colleagues

Regular or semi-regular searching on a database or Internet

Other, please specify

Please rank the top three methods you depend on for keeping up-to-date.

\section{Importance of keeping up-to-date}

As it might be expected from physicists and astronomers, the majority of respondents believed that it was important for them to keep up with the developments of their subfields (Figure 1). But the levels of importance were different. A quarter of respondents considered keeping up-to-date as absolutely critical for their research. Fifty-five per cent ticked the option "quite important”. Although, surprisingly, a very tiny minority, one respondent, maintained that keeping up-to-date was not important for him at all! Further investigation of the data showed that the respondent was a research fellow in TMP.

[end of page 449]

Figure 1. Percentage frequency distribution of importance level of keeping up-to-date

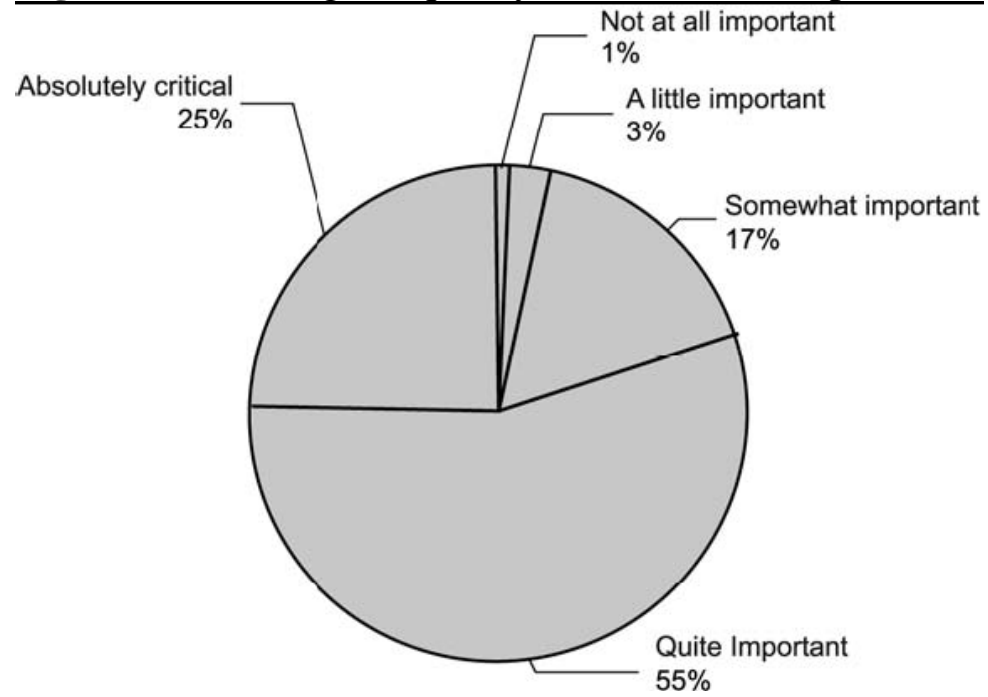


Figure 2. Percentage breakdown of importance level of keeping up-to-date by users' academic status

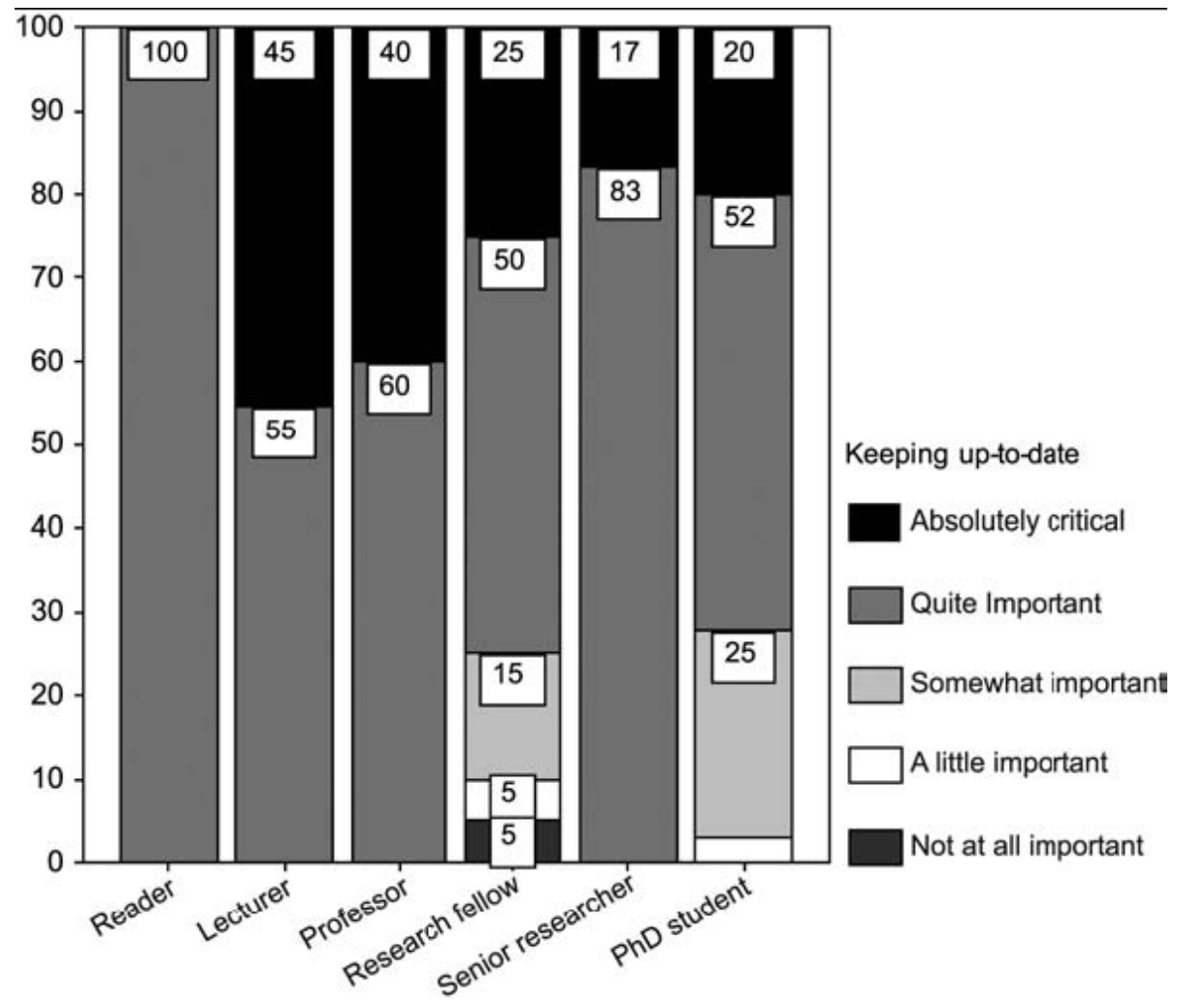

Looking at the academic status of the respondents (Figure 2), it turned out that those who associated less importance with keeping up-to-date were more likely to be $\mathrm{PhD}$ students or research fellows. About 3 per cent of $\mathrm{PhD}$ students and 5 per cent of research fellows considered keeping up-to-date a little important and one research [end of page 450] fellow surprisingly maintained that keeping up-to-date was not important at all for his/her research subfield.

The following sections present the different aspects of the findings of the survey with regard to the methods used for keeping up-to-date.

\section{Dependency on various methods}

A range of different methods were used for keeping up-to-date. The most popular methods turned out to be interpersonal communication methods. Word of mouth and colleagues, browsing e-journals, searching, conferences, and meetings were the methods on which respectively 93, 85, 83, 78 and 69 per cent of respondents were very or quite dependent. Search e-mail alerts, browsing print journals and e-print e-mail alerts were less popular methods (Figure 3). This finding was also somewhat reflected in the answers when respondents were asked to rank their top three most used methods for keeping up-to-date (Figure 4). Browsing e-journals, browsing e-print archives and meetings with respectively 25, 22 and 20 per cent were the most favourite methods among the first ranked methods. Although respondents did not favour receiving e-mail alerts from e-print archives, they did browse them. 
Figure 3. Percentage frequency distribution of dependency on various methods for keeping up-to-date

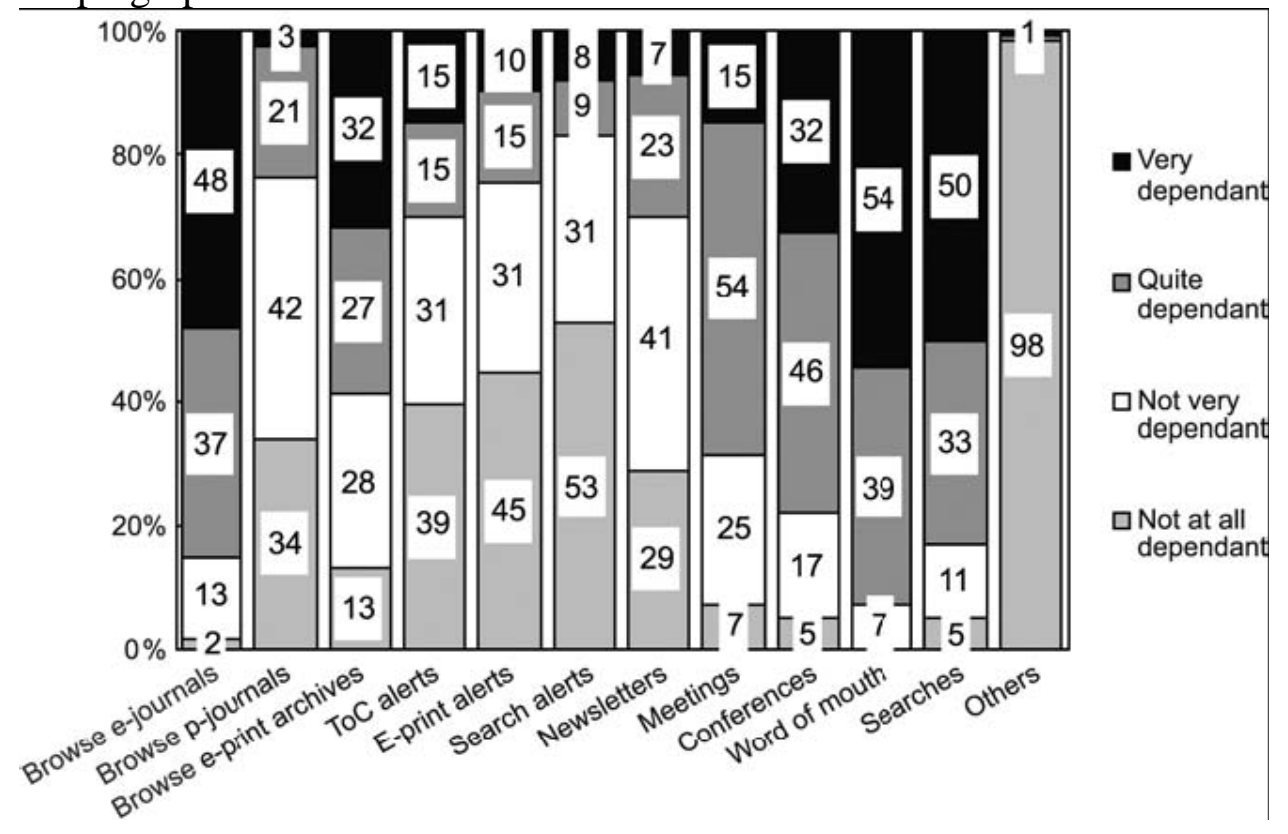

\section{By importance of keeping up-to-date}

Those for whom it was more important to keep up-to-date were more likely to use eprint and alerting services. All of those who used e-print archive e-mail alerts and 36 per cent of those who browsed e-print archives stated that it was absolutely critical for them to keep up-to-date. On the other hand those who relied on personal communications (meetings, conferences, word of mouth) and also newsletters were more likely to associate less importance with keeping up-to-date. Methods such as personal communications and newsletters perhaps have a less frequent nature and it is natural that those who rely on these methods associate less importance with keeping upto-date compared to those who rely on e-mail alerts and browsing that can be done on a daily basis (Figure 5).

\section{By academic status of participants}

Regarding the academic status of the participants (Figure 6), there were some interesting findings. Professors were the only [end of page 451] group who chose newsletters as their top ranked method for keeping up-to-date, with a tenth of them 
Figure 4. Percentage frequency distribution of the top three ranked methods for keeping up-to-date

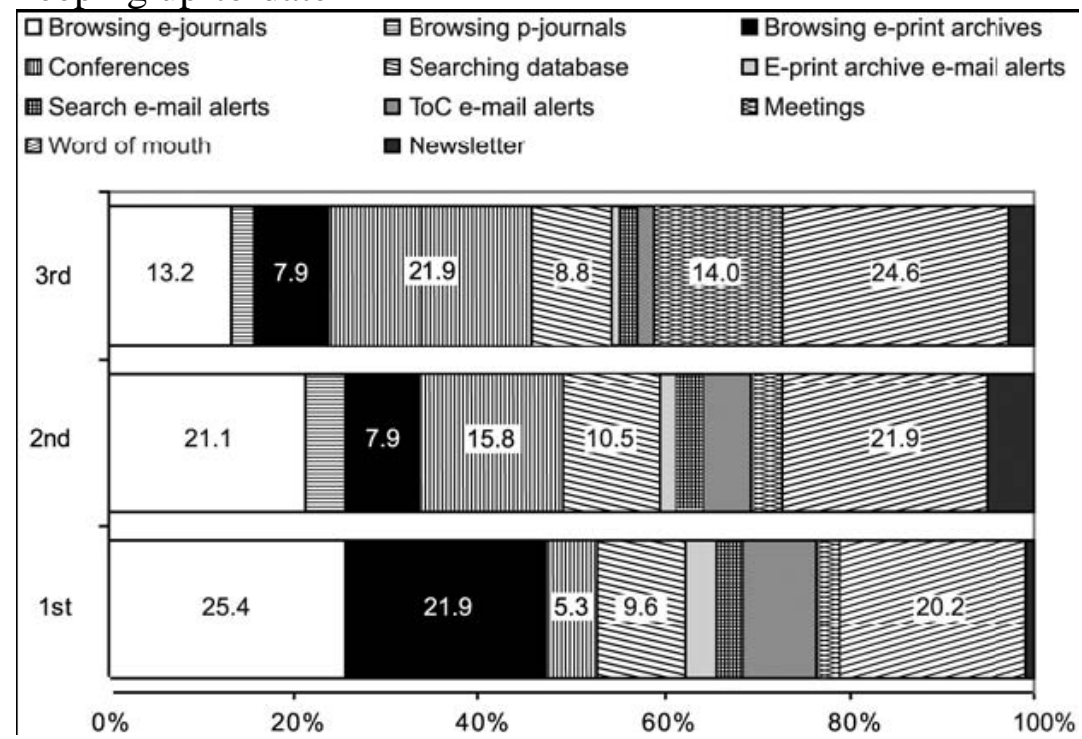

Figure 5. Percentage breakdown of the most used methods for keeping up-to-date by importance of keeping-up-to-date

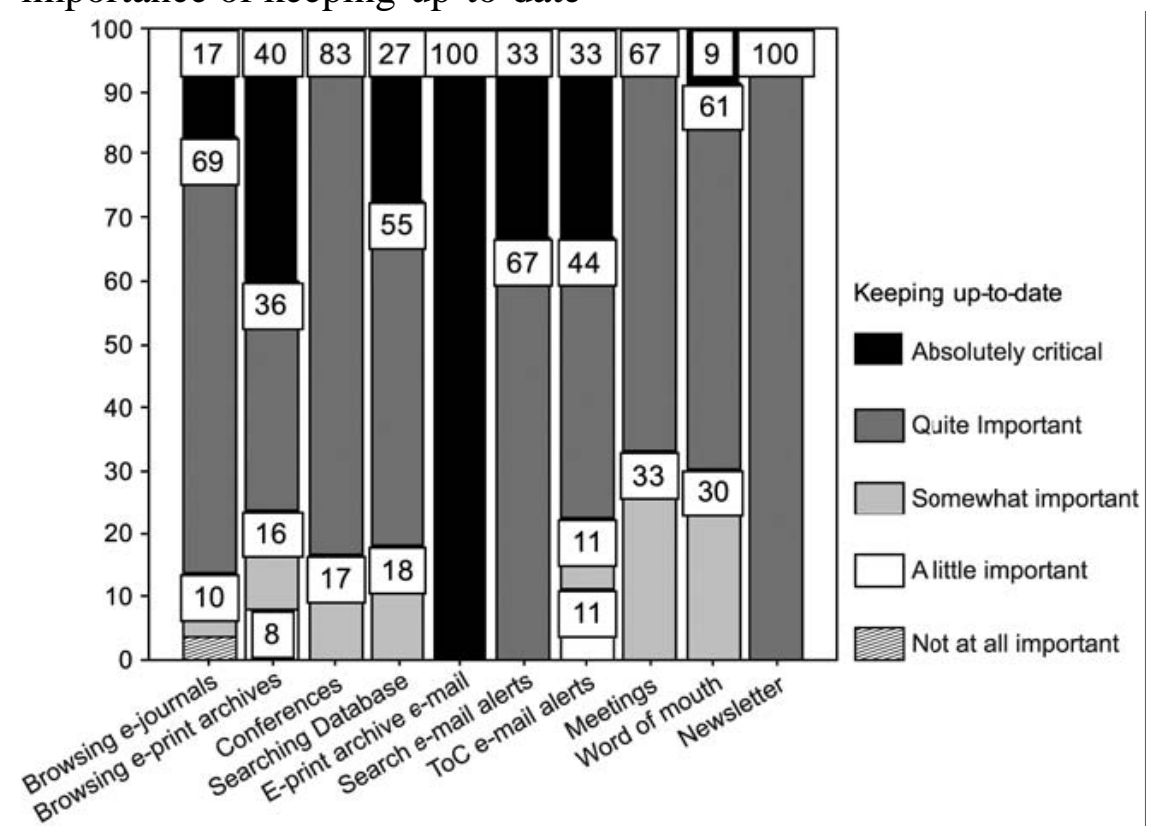

doing so. Word of mouth was popular among professors (30 per cent), PhD students (26 per cent) and senior researchers (17 per cent). Search e-mail alert was hardly used with just 5 per cent of students making use of it. Looking at the age of respondents it was revealed that the oldest group (60 and over) depended on [end of page 452] conferences more than the others did. A quarter of them ranked conferences as their first most used method for keeping up-to-date. Word of mouth was also an important method for keeping up-to-date for respondents above 50 years old. Perhaps it is expected that older academics rely more on personal communications such as word of mouth and conferences for keeping up-to-date compared to younger researchers. This is because older academics are expected to have a wider personal network and are more involved in their expert community through their longer academic careers while the younger ones may not have the privilege of access to a wide network of experts. Respondents 
between 35 and 39 years old depended more than any thing else on e-print archive email alerts, with two-fifth of them doing so.

Figure 6. Percentage breakdown of top ranked methods for keeping up-to-date by respondents' academic status

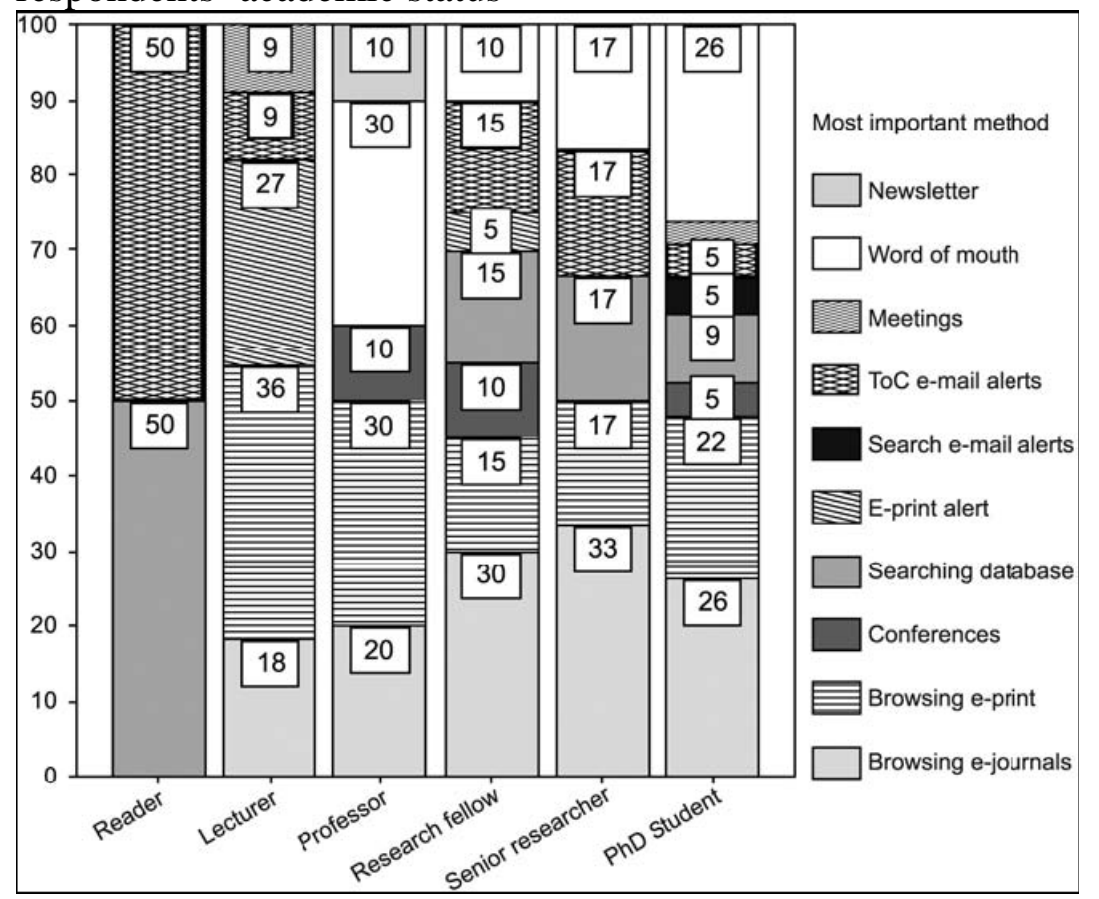

\section{By type of research}

The breakdown of the top most used methods for keeping up-to-date with the respondents' research type (Figure 7) revealed the effect of type of research on the methods used for keeping up-to-date. Physicists and astronomers who were involved in instrumentation kind of research relied on conferences more than anything else; half of them chose conferences as their top used method. ToC e-mail alerts and browsing ejournals ( 25 per cent each) were the other two methods this group used as their most favourite method. Unlike the other groups who all browsed e-print archives as their first method for keeping up-to-date, this method had no use for instrumentalists as the first option. Theorist and experimentalist physicists resembled each other as they both relied considerably on browsing e-journals (28 per cent and 27 per cent respectively) and browsing e-print archives (17 per cent and 27 per cent respectively). However, they differed in that theorists [end of page 453] made more use of word of mouth and meetings compared to experimentalists. Those whose research was a combination of both theory and experiment made the most of word of mouth, with 60 per cent of them opting for it as their first priority for keeping up-to-date. Astronomers who were involved in observation also depended on word of mouth (23 per cent), browsing e-print archives (23 per cent) and browsing e-journals (15 per cent). A notable difference between this group and the other group was that they were the only group who chose newsletters as their most favourite method for keeping up-to-date, 8 per cent of them did so. Theorist astronomers and astrophysicists' main difference with the other groups was their higher rate of using e-print archive e-mail alerts (17 per cent). 
Figure 7. Percentage breakdown of top ranked methods for keeping up-to-date by type of research respondents

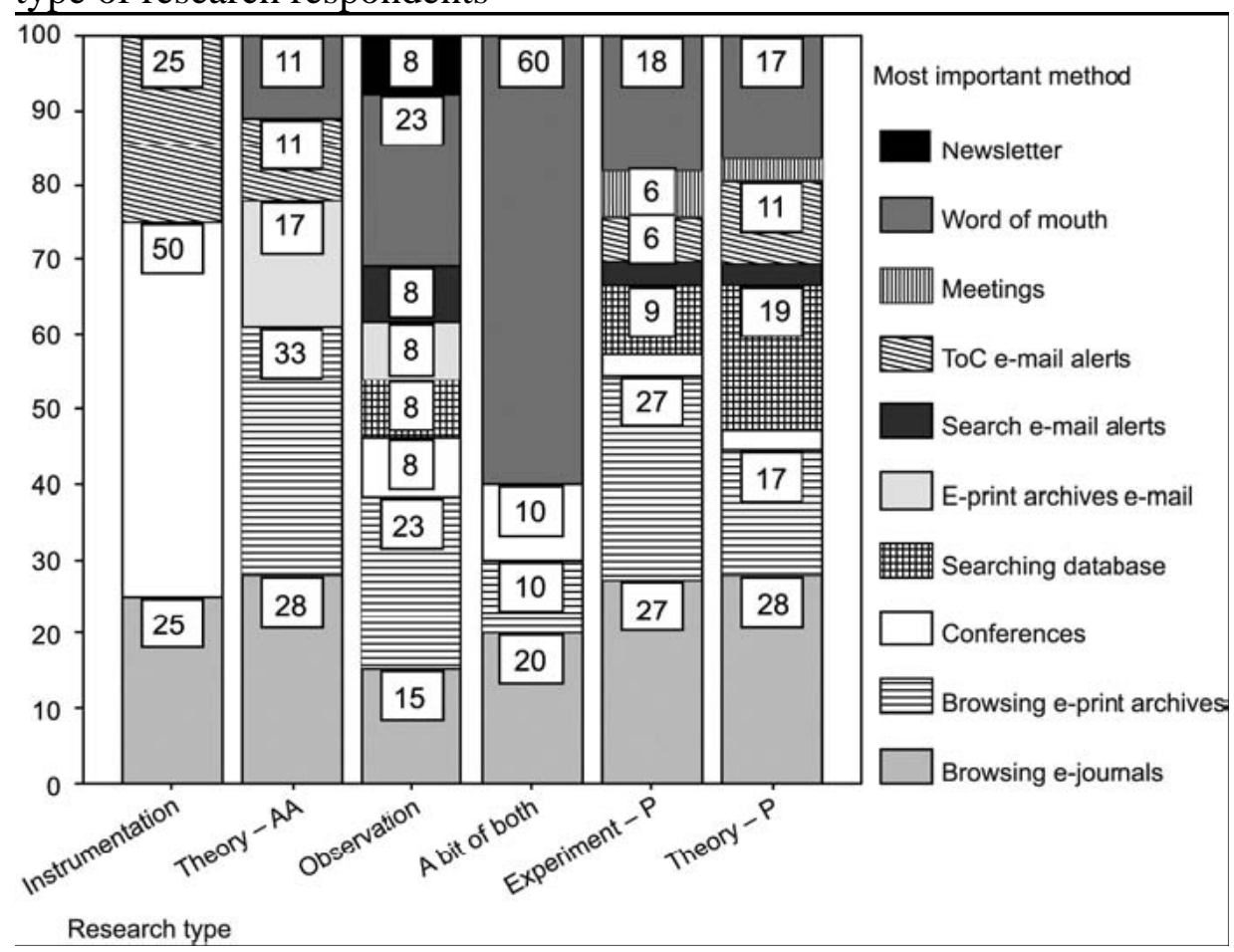

\section{By research group}

Figure 8 gives the percentage frequency distribution of top ranked methods for keeping up-to-date by respondents' research group. Respondents from the Optical Science Lab relied a great deal on conferences; about two-thirds did so. Astronomers and Astrophysicists were the only group who relied partly on newsletters (5 per cent) and eprint archive e-mail alerts (18 per cent) for keeping up-to-date. Five per cent of them used newsletters as their main method for keeping abreast. The highest reliance on departmental meetings (11 per cent) belonged to High Energy Physics. This group also relied on word of mouth more than the other groups did (39 per cent). Respondents in Theoretical Molecular Physics searched databases for keeping up-to-date more than any other group did; 27 per cent of them depended on this method as their main method for keeping up-to-date.

[end of page 454] 
Figure 8. Percentage breakdown of the top ranked methods for keeping up-to-date by respondents' research group

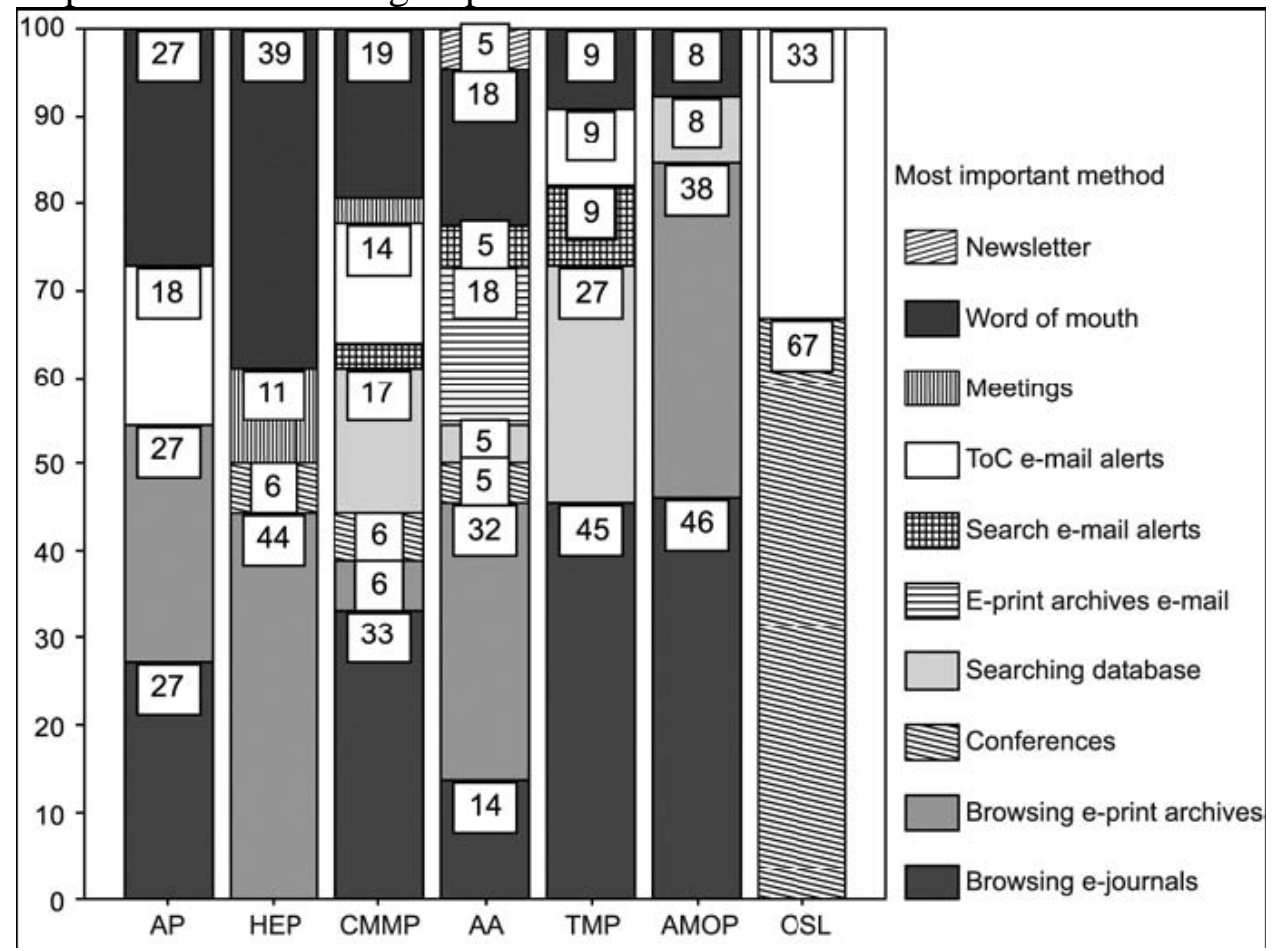

\section{Finding research articles}

The results presented in this section are based on the following four questions that the participants were asked:

How often do you use each of these methods for identifying research articles?

(Frequency: Daily/ 2-3 times a week/ About once or twice a month/ Less than once a month/ Never)

Recommendation from friends

Table of contents e-mail alerts

Browsing or searching journals' web sites

Following up references at the end of papers

Searching in a general database such as Web of Knowledge

Searching in a subject specific database such as ADS, Spires, Inspec

Searching Google for words or authors (this doesn't include when you search Google to find a journal's web site)

Searching Google Scholar

Other

By which of the above-mentioned methods do you identify the highest number of articles you read?

Please, think of the scholarly article you read most recently. How did you identify the last article you read?

Through a colleague

Through e-mail alert

[end of page 455]

Through browsing a journal's web site

Through references of another paper 
Through a search on Google

Through a search on Google Scholar

Through a search in an abstract database (e.g., Web of Science, Spires)

I had read it before and was rereading it, so I already knew about it

Other, please specify

How old was that paper? (A few weeks/ A few months/ 1 year/ 2 years/ 3 years/ 4-5 years/ 6-10 years/ $11-15$ years/ More than 15 years).

\section{Frequency of use of different methods}

Regarding the frequency by which different methods were used for identifying research articles (Figure 9), Google stood on the top with 18 per cent of respondents using it on a daily basis. Searching subject databases (11 per cent), browsing or searching e-journal web sites ( 9 per cent) and tracking references at the end of articles (8 per cent) were the other highly used methods on a daily basis. Tracking references at the end of papers turned out to be the most popular method with 61 per cent of respondents who used it daily or 2-3 times a week, followed by Google (58 per cent). Forty-six per cent of the respondents never used Google Scholar for identifying research articles. This figure was 35 per cent for ToC e-mail alerts.

Figure 9. Percentage frequency distribution of methods used for identifying articles

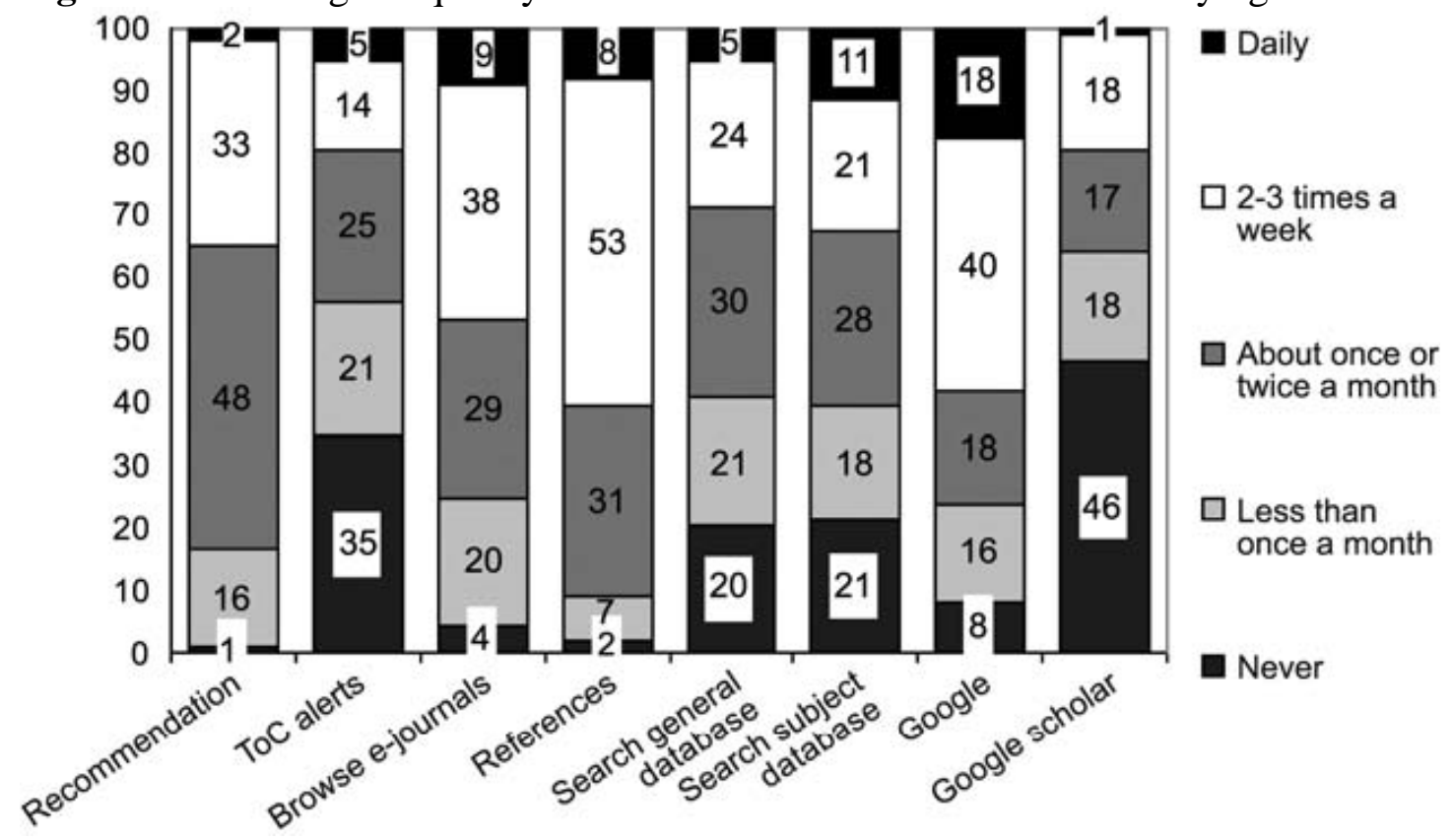

\section{The last article read}

The most used method for finding the last article read (Figure 10) was recommendations by colleagues through which more than a third of the last articles read were found. Tracking references (20 per cent) and searching databases (13 per cent) was the second and the third most used methods. While the previous figure showed that Google was the most frequently used method, this figure shows that only a tenth of the last articles read were found through using Google web searching, which is still a considerable portion considering that Google is not designed for and is not meant to be used for finding scholarly articles. Only three per cent of the last articles read were a reread. 
Figure 10. Percentage frequency distribution of methods used for identifying last read article

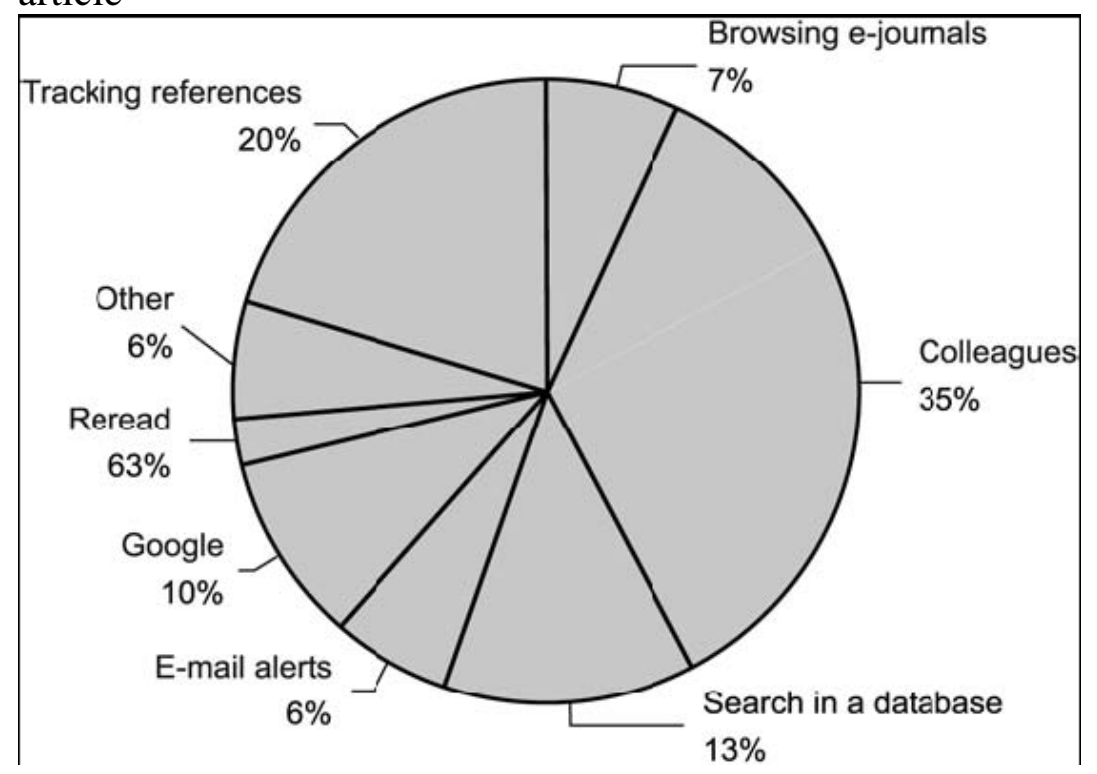

\section{By users' academic status}

There were some differences among respondents with different status with regard to the most used methods for identifying articles. Lecturers exploited "searching subject databases" more than the other respondents did. Thirty-six per cent of lecturers used this method as their main method for identifying articles (Figure 11). Searching Google Scholar was not popular at all. Less than 3 per cent of PhD students relied on Google Scholar, but it has to be born in mind that the new studies (Hemminger et al., 2007) already show the increasing popularity of Google Scholar since this survey was conducted. Tracking references at the end of articles was the favourite method for identifying articles for 50 per cent of professors.

\section{By users' type of research}

Type of research refers to whether the research conducted by the participants was experimental, theoretical, observational and so on. Looking at the type of research and the most used method for identifying articles we could see a high reliance of instrumentalist physicists on tracking references (75 per cent). Thirty-six per cent of theoretical physicists also relied on this method for identifying research articles (Figure 12). Searching subject databases was the most used method for theoretical astronomers (39 per cent), observational astronomers (38 per cent) and those physicists whose research combined both theory and experiment (30 per cent). This difference can have different reasons including the availability of the databases in the field as well as other reasons. For example, the high reliance of theoretical physicists on reference tracking might be because it is an efficient method for tracking an idea or a theory in the literature. However, this is an area that merits further investigation.

\section{By age of article}


Figure 13 visualises the percentage breakdown of age of the last read article by methods used for finding it. Generally older articles tended to be identified through means such as colleagues' recommendation and tracking references. None of the articles older than five years was found through browsing. Surprisingly 50 per cent of the articles more than 15 years old were found using Google. This result confirms the findings of Nicholas et al. (2005b) and Huntington et al. (2006) that online availability and use of search facility leads to more use of older articles.

[end of page 457]

Figure 11. Percentage breakdown of the most used methods for identifying articles by respondents' academic status

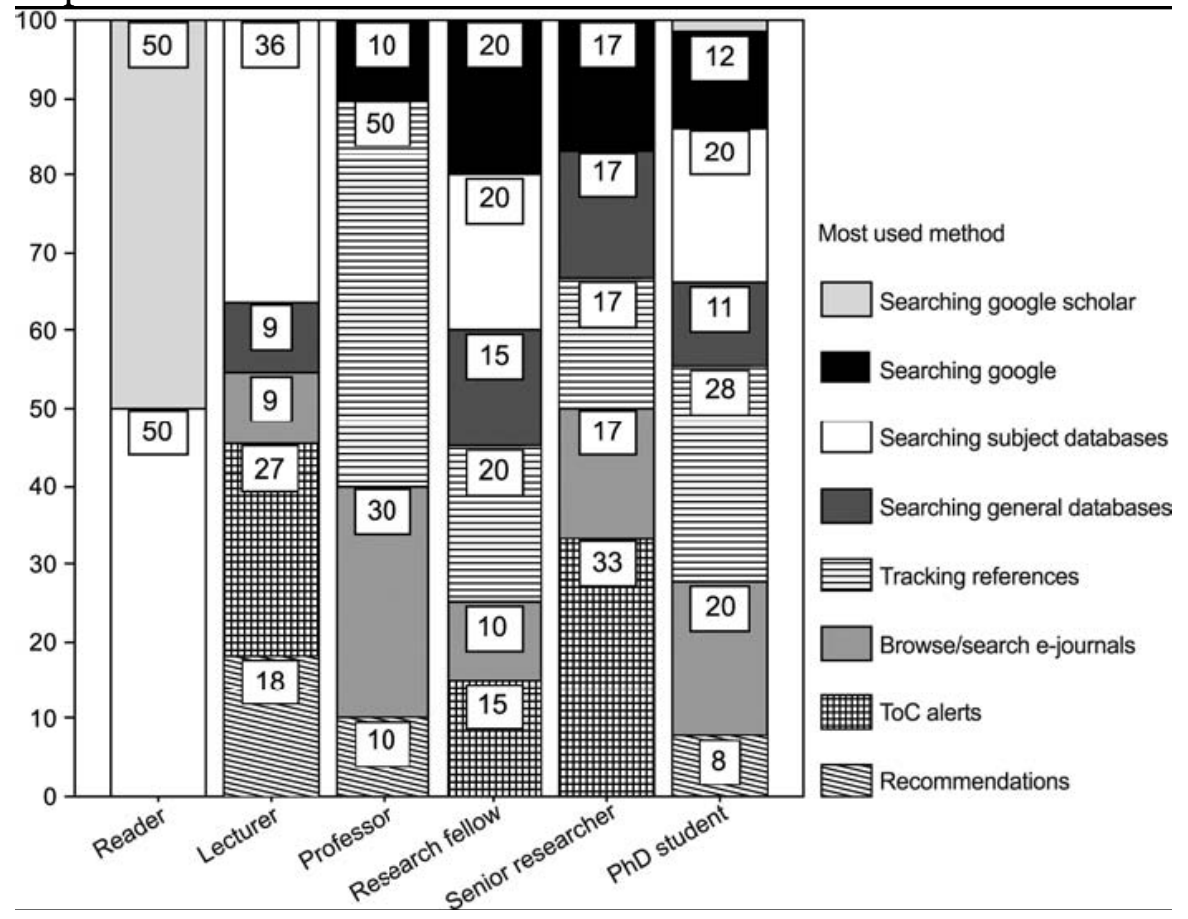

\section{By users' research group}

Tracking references and recommendations by colleagues were the two most used methods for identifying the last article read for most of the research groups. Respondents in CMMP made more use of searching databases (25 per cent) than the other research groups did. TMP physicists used Google (27 per cent) more than any other research group did. E-mail alert was used only by three research groups including AA (14 per cent), HEP (11 per cent), and CMMP (6 per cent). High usage of e-mail alerts by these groups can be attributed to the good e-mail alerting services that are available in these areas through arXiv and the other sources. Figure 14 relates.

\section{Conclusions}

The findings presented here show that, although similarities exist among subfields of physics and astronomy with regard to information-seeking behaviour, there are significant differences as well. The subfields of physics and astronomy are different in terms of their reliance on different methods used for keeping up-to-date as well as methods used for finding articles. Most of the articles read by people in Astronomy and Astrophysics (AA) are identified through recommendations by colleagues, searches in databases and e-mail alerts. AA relied on browsing e-print archives, e-print e-mail alerts and word of mouth in order to keep up-to-date. People in AMOP relied a great deal on 
using journal web sites as well as searching Google for finding articles they read. Browsing e-journals and browsing e-print archives were the two most used methods for keeping up-to-date with the developments in their field. AP physicists [end of page 458]

Figure 12. Percentage breakdown of the most used methods for identifying articles by type of research of respondents

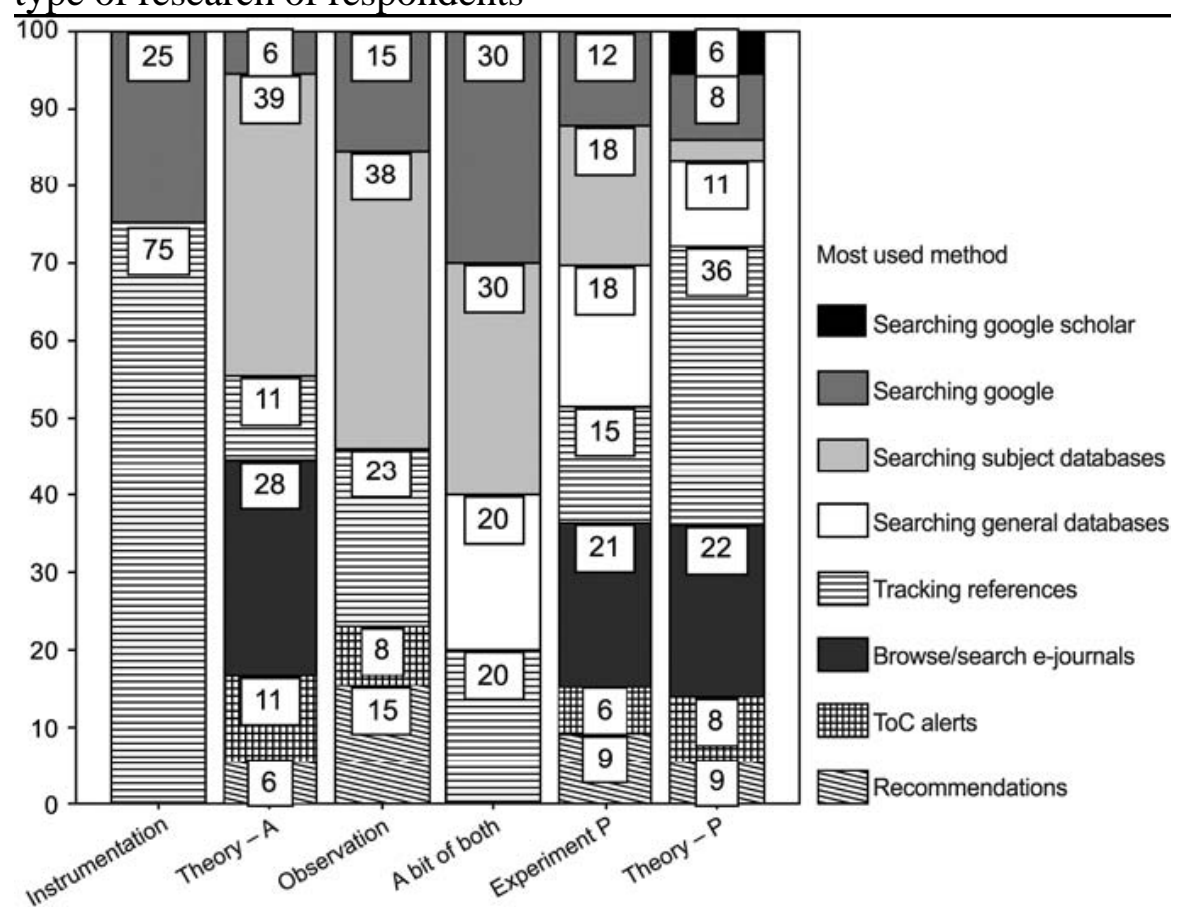

Figure 13. Percentage breakdown of age of last read article by methods used for finding it

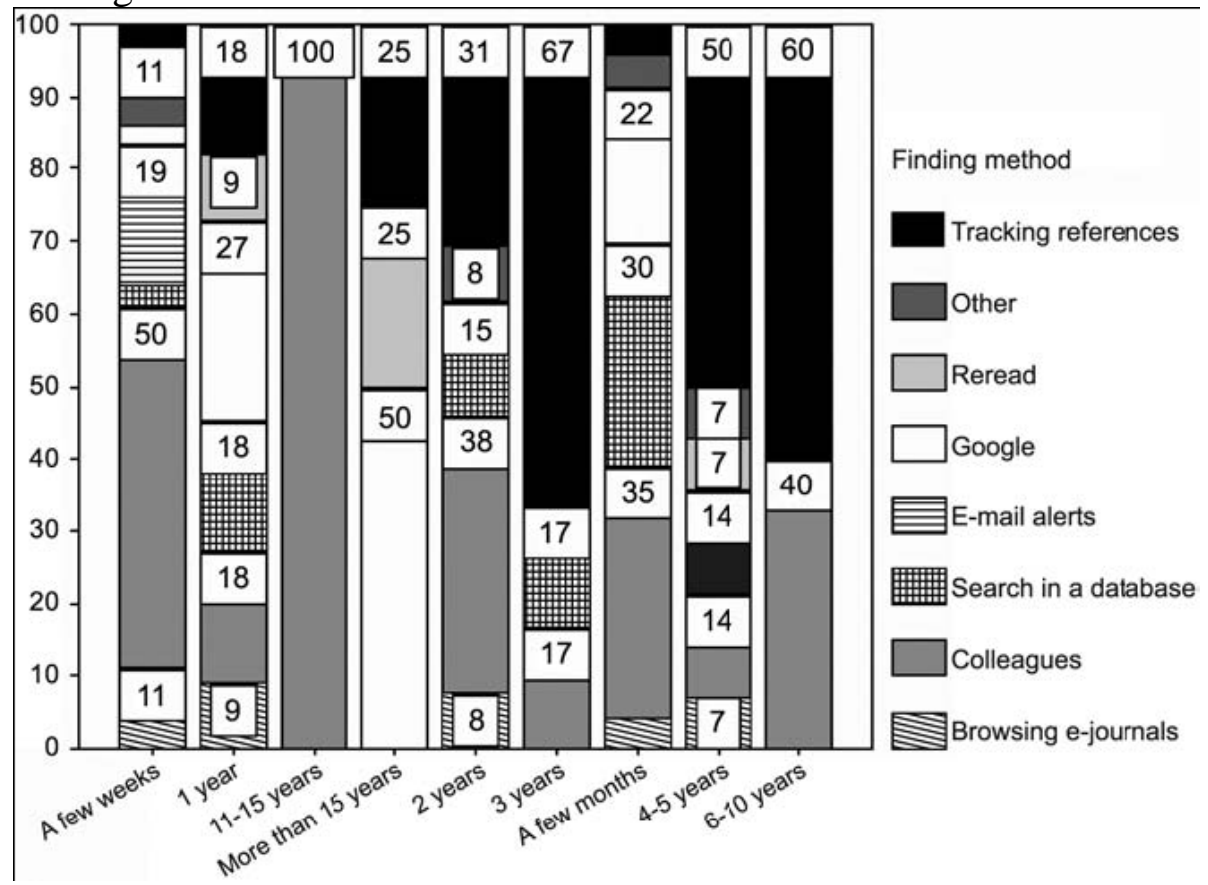

[end of page 459] 
relied on colleagues and reference tracking for finding articles they read. However, word of mouth, browsing electronic journals and e-print archives were the main sources of information in order of importance for keeping up-to-date. Physicists in CMMP mainly used recommendations by their colleagues, conducting searches in general databases and tracking references for identifying articles they read. In addition they tended to browse electronic journals, rely on word of mouth, search databases and receive journals' table of contents e-mail alerts in order to keep up-to-date. Physicists in HEP relied mostly on searches in subject databases (arXiv.org) for identifying articles they read. The second most used method was searching in Google. The fact that Google was the second used means by which articles were found in the field of HEP might be because of high availability of open access material in HEP that makes everything searchable by general search engines such as Google. In order to keep up-to-date with the developments in HEP they mainly depended on browsing e-print archives, word of mouth and meetings. Physicists of OSL relied on tracking references and colleagues for identifying articles they read. Attending conferences and receiving table of contents email alerts were the two main methods on which they relied for keeping up-to-date. Finally, the researchers in TMP relied mainly on tracking references for finding articles they read. Browsing electronic journals and searching databases were the two main methods used for keeping up-to-date by the researchers in this group.

Figure 14. Percentage breakdown of methods used for finding last article read by respondents' research group

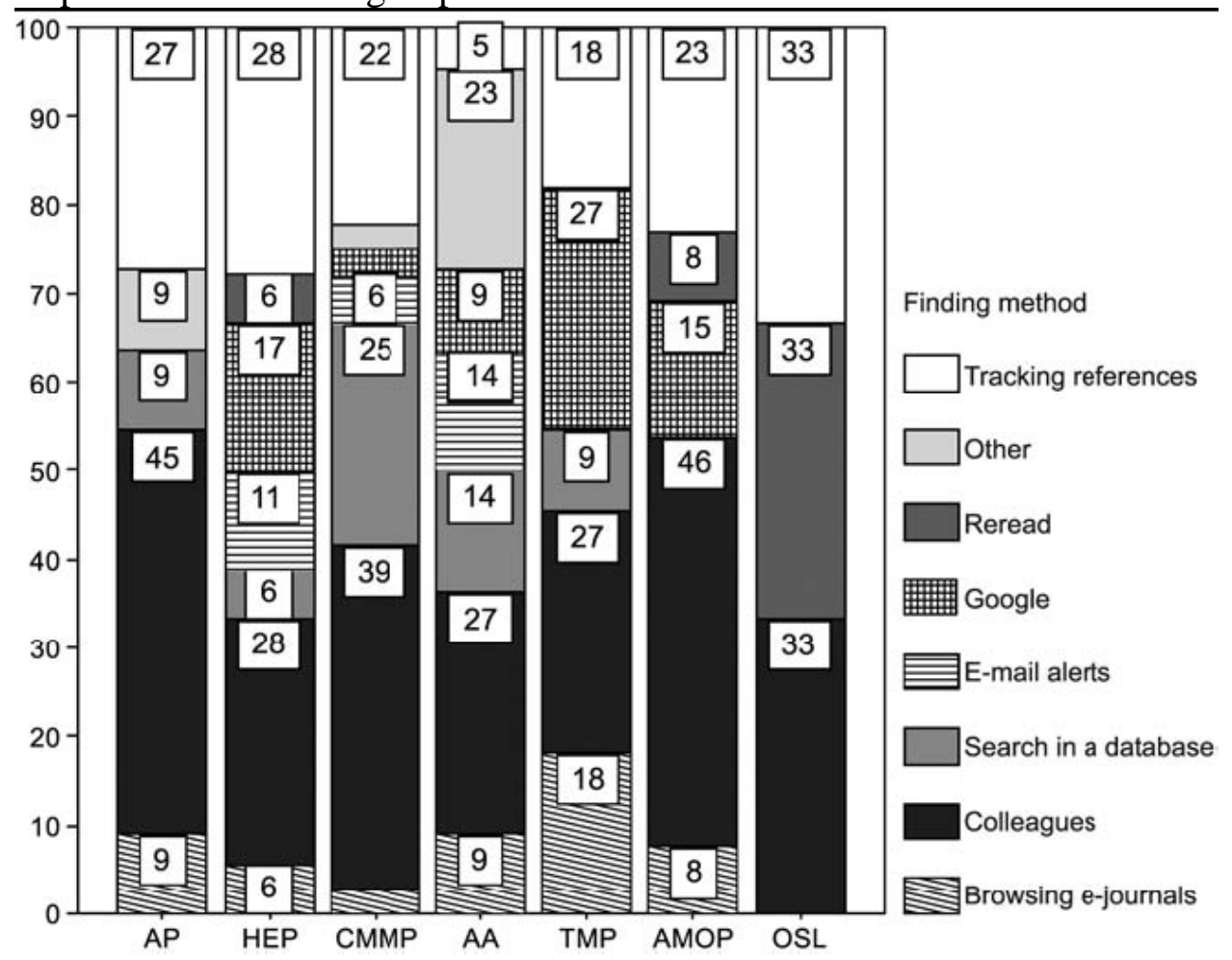

The study lends support to the findings of Brown (1999b) that showed high usage of citation tracking. It also confirms some of the findings by Nicholas et al. (2006) that showed physicists, compared to scientists in some other subjects, were more likely to [end of page 460] be browsers. However, as we can see, different subfields are different and talking of physicists here might be over-generalising the data. The study highlights the need for and the value of looking at narrower subject communities within disciplines for a deeper understanding of the information behaviour of scientists. 
The study also revealed differences in information-seeking behaviour among people with different academic status. Those with higher academic status, such as professors, relied more on word of mouth and interpersonal communications such as conferences for keeping up-to-date, while $\mathrm{PhD}$ students were more likely to use alerting services.

\section{References}

Brown, C.M. (1999a), "Information literacy of physical science graduate students in the information age”, College and Research Libraries, Vol. 60 No. 5, pp. 426-438.

Brown, C.M. (1999b), "Information seeking behavior of scientists in the electronic information age: astronomers, chemists, mathematicians, and physicists”, Journal of the American Society for Information Science, Vol. 50 No. 10, pp. 929-943.

Cho, A. (2000), “Distorted galaxies point to dark matter”, Science, Vol. 287 No. 5460, pp. 1899-1901.

Ellis, D., Cox, D. and Hall, K. (1993), "A comparison of the information seeking patterns of researchers in the physical and social sciences", Journal of Documentation, Vol. 49 No. 4, pp. 356-369.

Fry, J. (2003), The Cultural Shaping of Scholarly Communication within Academic Specialisms, unpublished $\mathrm{PhD}$ thesis, University of Brighton, Brighton.

Gobo, G. (2004), "Sampling, representativeness and generalizability”, in Seale, C., Gobo, G., Gubrium, J.F. and Silverman, D. (Eds), Qualitative Research Practice, Sage, London, pp. 435-456.

Gould, C.C. and Pearce, K. (1991), Information Needs in the Sciences: An Assessment, Research Library Group, Mountain View, California.

Hemminger, B.M., Lu, D., Vaughan, K.T.L. and Adams, S.J. (2007), "Information seeking behavior of academic scientists", Journal of the American Society for Information Science and Technology, Vol. 54 No. 14, pp. 2205-2225.

Huntington, P., Nicholas, D., Jamali, H.R. and Tenopir, C. (2006), “Article decay in the digital environment: a usage analysis by date of publication employing deep log methods", Journal of the American Society for Information Science and Technology, Vol. 57 No. 13, pp. 1840-1851.

Jamali, H.R. (2008), Information-seeking behaviour of physicists and astronomers: an intradisciplinary study, unpublished $\mathrm{PhD}$ thesis, University College London, London.

Kling, R. and McKim, G. (2000), "Not just a matter of time: field differences in the shaping of electronic media in supporting scientific communication”, Journal of the American Society for Information Science and Technology, Vol. 51 No. 14, pp. 1306-1320.

Lawal, I. (2002), "Scholarly communication: the use and non-use of e-print archives for the dissemination of scientific information, Issues in Science and Technology Librarianship, Vol. 36, available at: http://www.istl.org/02-fall/index.html (accessed 25 November 2007).

Nicholas, D., Huntington, P., Dobrowolski, T., Rowlands, I., Jamali, H.R. and Polydoratou, P. (2005b), "Revisiting 'obsolescence' and journal article 'decay' through usage data: an analysis of digital journal use by year of publication", Information Processing \& Management, Vol. 41 No. 6, pp. 1441-1461.

Nicholas, D., Huntington, P. and Jamali, H.R. (2006), “Authors as users: a deep log analysis linking demographic and attitudinal data obtained from scholarly authors with their usage of ScienceDirect”, Ciber, University College London, London. 
Nicholas, D., Huntington, P., Rowlands, I., Jamali, H.R. and Haynes, J. (2005a), “An investigation of physicists' information-seeking behaviour, publishing practices, and views on the scholarly publishing system: with special reference to the Institute of Physics and its journals”, report of an international survey”, CIBER, University College London, London.

[end of page 461]

Royal Society (1948), Royal Society Scientific Information Conference, London.

Tenopir, C. and King, D.W. (2002), "Reading behaviour and electronic journals", Learned Publishing, Vol. 15 No. 4, pp. 259-265.

Wertman, E.R. (1999), Electronic Preprint Distribution: A Case Study of Physicists and Chemists at the University of Maryland, unpublished MSc thesis, Virginia Polytechnic Institute and State University, Blacksburg, VI.

[end of page 462] 